Original Article

\title{
MARKET SAMPLE SURVEY OF CROCUS SATIVUS LINN. TO ASSESS THE GENUINITY FOR USING ANTIOXIDANT ACTIVITY, TOTAL PHENOLIC CONTENT AND HIGH-PRESSURE THIN LAYER CHROMATOGRAPHY USING DETECTION OF FLAVONOIDS
}

\author{
K. R. ATHIRA ${ }^{1}$, T. V. BINU ${ }^{2}$ \\ ${ }^{1}$ Department of Botany, Vimala College (Autonomous) Thrissur-9, Kerala, India, ${ }^{2}$ St. Joseph College (Autonomous), Iringalakuda, Thrissur-9, \\ Kerala, India \\ Email: athirakramachandran37@gmail.com
}

Received: 15 Nov 2018, Revised and Accepted: 20 Feb 2019

\begin{abstract}
Objective: Herbalism is a traditional medicine or folk medicine practice based on the use of plants and plant extracts. Many of the drugs used in conventional medicine are dried from herbs. Despite the fluctuation in prices in international markets, saffron was still remained the most expensive spice. The main aim of this study is to examine the antioxidant activity, total phenolic content, high-pressure thin layer chromatography using flavanoid analysis and adulteration detection of saffron. Crocus sativus. Linn is a perennial stemless herb of the Iridaceae family. Saffron stigmas of sample1, sample2, sample3and sample4 are collected from different rates of the market sample from Thrissur district, sample5 collected from the Oushadhi premises, and it is collected from Himachal Pradesh.
\end{abstract}

Methods: In this study detecting the antioxidant activity, total phenolic content, high-pressure thin layer chromatography using flavanoid analysis of different samples of saffron stigmas. The extracts were prepared by using ethanol as a solvent.

Results: Safranal is present only in s5 sample. It is the main essential volatile oil responsible for the saffron characteristic such as odour. Phenolic content is varied in different market samples. The amount of phenolic compounds in the saffron extract was determined using the Folin-ciocalteau reagent. Total phenolic content is the help to detect the pure and fake saffron. The phenolic content is higher in S5. Sample S5 showed 0.737 mg/ml phenolic content. Lowest level of phenolic content in sample S3. Sample S3 showed $0.0887 \mathrm{mg} / \mathrm{ml}$ phenolic content. Sample S4 showed $0.564 \mathrm{mg} / \mathrm{ml}$ total phenolic content. Sample S1 showed $0.416 \mathrm{mg} / \mathrm{ml}$ total phenolic content and sample S2 showed $0.267 \mathrm{mg} / \mathrm{ml}$ phenolic content. Antioxidant activity is higher in sample s5. and it is different in different market samples. Sample 5 stigma posses higher antioxidant activity. Sample S5 showing $14.88 \%$ antioxidant activity in $100 \mathrm{mg} / \mathrm{ml}$ concentration, $7.26 \%$ in $80 \mathrm{mg} / \mathrm{ml}$ concentration, $2.23 \%$ in $60 \mathrm{mg} / \mathrm{ml}$ concentration, $2.21 \%$ in $40 \mathrm{mg} / \mathrm{ml}$ and $1.01 \%$ in $20 \mathrm{mg} / \mathrm{ml}$ concentration. Sample S3 showed the lower antioxidant activity in $0.1 \%$ in $60 \mathrm{mg} / \mathrm{ml}$ concentration and $0.1 \%$ in $80 \mathrm{mg} / \mathrm{ml}$. Ascorbic acid standard showing $14.89 \%$ in $100 \mathrm{mg} / \mathrm{ml}$ concentration, $7.26 \%$ in $80 \mathrm{mg} / \mathrm{ml}$ concentration, $4.56 \%$ in $60 \mathrm{mg} / \mathrm{ml}$ concentration, and $3.1 \%$ in $40 \mathrm{mg} / \mathrm{ml}$ concentration, and $1 \%$ in $20 \mathrm{mg} / \mathrm{ml}$ concentration. Flavonoid content is different in different samples. It is present highly present in sample s1 and s5. sample s3 do not contain the Flavanoid. The quality of the samples depend on the price values.

Conclusion: The authenticity of saffron is an extremely important matter for the industry and for the consumers in view of security and protection,quality assurance, active properties and last but not least, economic impact. Despite the fluctuation in prices in international markets, saffron was and still remains the most expensive spice. The genuine saffron samples possess higher price value. The fake saffron available in the market with lower price value. The quality of the saffron depends upon the price values. These observations would be of immense value in the botanical identification and standardization of the drug in crude form and would help to distinguish the drug from its other spices.

Keywords: Crocus sativus, Antioxidant activity, Total phenolic content, High Pressure Thin Layer Chromatography

(c) 2019 The Authors. Published by Innovare Academic Sciences Pvt Ltd. This is an open access article under the CC BY license (http://creativecommons.org/licenses/by/4.0/) DOI: http://dx.doi.org/10.22159/ijcpr.2019v11i2.33021

\section{INTRODUCTION}

Saffron consists of dried trilobed stigmas of Crocus sativus Linn., which is a bulbous perennial with a globular corms; the plant is only 15-25 $\mathrm{cm}$ high, native of Southern Europe and cultivated in Mediterranean countries, particularly in Spain, Austria, France, Greece, England, Turkey and Persia, Iran, India (Jammu and Kashmir)and the orient. True saffron must not be confused with either meadow saffron (Colchicum autumnale Linn. family: Lilliaceae) or safflower or bastard saffron (Carthamus tinctorium, Family: Compositae), which are occasionally used as adulterants of true saffron. Saffron is one of the oldest and certainly among the world's most expensive species [1, 2].

Recent interest in antioxidant due to their involvement in the health benefit had led to the development of a number of antioxidant capacity assays. Plants contain a high concentration of numerous redox active secondary metabolites or antioxidants, such as ascorbic acid, carotenoids, glutathione, tocopherols, tocoterienols and enzyme with high antioxidant activity to help them protect against hazardous oxidative damage [3]. The simple definition of an antioxidant as described by Halliwell is "a molecule which, when present in small concentrations compared to that of an oxidizable substrate, significantly delays or prevents the oxidation of the substrate" However, in row material trade unintentional adulteration also exists 4 . Different methods have been employed for the assessment of quality and detection of adulteration in saffron [4]. India has a rich wealth of important medicinal flora and its varied climate is ideally suited for the cultivation of medicinal plants. One of the major drawbacks in popularization of plantbased drugs is the inconsistent quality of the formulated preparations [5]. In addition to qualitative detection; it provides semi-quantitative information on the main active constituents of plant preparations.

\section{MATERIALS AND METHODS}

Materials

\section{Collection of samples}

The Crocus sativus Linn, stigmas of sample1, sample2, sample3, sample4 of varying price were collected from the market of Thrissur district. Sample 5 stigma collected from Oushadhi, which was collected from Himachal Pradesh on order (Plate 2).

\section{Sample details}

S1-Market sample from Thrissur district (1 gm=160RS) 
S2-Market sample from Thrissur district (1 gm=100RS)

S3-Market sample from Thrissur district (1 gm=55RS)

S4-Market sample from Thrissur district (1 gm=300RS)

S5-Market sample from Himachal Pradesh (1 gm=1500RS)

Extraction: The extracts of samples were prepared by using the solvents water, ethanol and methanol.

\section{TLC identity test-detecting the presence of saffranal [6]}

Macerate $1 \mathrm{~g}$ dried powdered drug with $10 \mathrm{ml}$ of n-hexane overnight. Filter and remove the solvent under reduced pressure. Dissolved the residue in $10 \mathrm{ml}$ of $\mathrm{n}$-hexane. It is the formation of the test solution. Standard solution is made up of dissolving $1 \mathrm{mg}$ of safranal in $10 \mathrm{ml}$ of n-hexane. Toluene: Ethyl acetate (9.3:0.7) using as a solvent system. Apply five micro $\mathrm{ml}$ of test solution separately on a precoated silica gel 60 F254 TLC plate of the uniform thickness of 0.2 $\mathrm{mm}$. develop the plate in the solvent system in a twin through the chamber to a distance of $8 \mathrm{~cm}$. spray the plate with anisaldehydesulphuric acid reagent and heat at $105^{\circ}$ for 5 to 10 minute. Record the $\mathrm{RF}$ value and colour of the resolved bands [6].

\section{Total phenolic content [7]}

The total phenolic content was expressed in milligrams of gallic acid equivalents per gram of extract. Prepare a stock solution $(1 \mathrm{mg} / \mathrm{ml})$ of the extract in methanol. From the stock solution, take suitable quantity of the extract into $25 \mathrm{ml}$ volumetric flask and add $10 \mathrm{ml}$ of water and $1.5 \mathrm{ml}$ of folin ciocalteau reagent. Keep the mixture for $5 \mathrm{~min}$ and then add $4 \mathrm{ml}$ of $20 \%$ sodium carbonate solution and makeup to $25 \mathrm{ml}$ with double distilled water keep the mixture for $30 \mathrm{~min}$ and record absorbance at $765 \mathrm{~nm}$. The total phenolic content was calculated with the help of standard curve equation and the formula given below.

Total phenolic content $(\% \mathrm{w} / \mathrm{w})=\left(\mathrm{GAE} \times \mathrm{V} \times \mathrm{D} \times 10^{-6} \times 100\right) / \mathrm{W}$

Where, GAE-Gallic acid equivalent $(\mu \mathrm{g} / \mathrm{ml}), \mathrm{V}$-Total volume of sample (ml), D-Dilution factor, W-Sample weight (gm).

\section{Antioxidant activity \\ DPPH radical scavenging assay}

This spectroscopic assay uses the stable radical, DPPH as a reagent. The Hydrogen atom or electron donating abilities of the compounds and some untainted compounds can be measured from the bleaching of the purple colored Methanol solution of 2,2-diphenyl-1-picrylhydrazyl (DPPH). Preparing the different concentrations of standard solution ascorbic acid, and preparing the plant extract solutions in ethanol and preparing the $0.3 \mathrm{mmol}$ solution of DPPH in $100 \%$ ethanol to $1 \mathrm{ml}$ of this solution add $3 \mathrm{ml}$ of the sample extract. The same reaction mixture without the extract sample but with an equivalent amount of standard phosphate buffer should serve as control. Shake the mixture and allow to stand at room temperature for $30 \mathrm{~min}$. Measure the absorbance of the reaction mixtures at $517 \mathrm{~nm}$. determine the percentage scavenging activity at different concentrations [8].

$$
\% \text { of scavenging activity }=A_{0}-A_{1} / A_{0} * 100
$$

$\mathrm{A} 0=$ Absorbance value of the blank sample or control, $\mathrm{A} 1=\mathrm{Absorbance}$ of the test sample

\section{High-pressure thin layer chromatography (HPTLC)-detection of flavonoids}

HPTLC is an enhanced form of thin layer chromatography (TLC). HPTLC enables simultaneous analysis of many samples in less time with better analytical precision and accuaracy. Flavonoid standard Rutin is used for the HPTLC method $[8,9]$. The Samples are prepared by the given method such as, $0.5 \mathrm{gm}$ of the sample is taken and adding $3 \mathrm{ml}$ methanol and sonicate in $30 \mathrm{~min}$. Then it is filtered and injected to HPTLC. $20 \times 10 \mathrm{~cm}$ HPTLC plate (HPTLC silica gel $60 \mathrm{~F} 254$ ) was activated at $110^{\circ} \mathrm{C}$ for 30 minute uses. $2000 \mu \mathrm{l}$ of the extract was then applied as a single band of $180 \mathrm{~mm}$ length on the activated HPTLC plate. The Stationary phase is used as silica gel $60 \mathrm{~F} 254$, and HPTLC plates. Mobile phase is prepared by using Ethyl acetate: Glacial acetic acid: Formic acid: Water in the ratio (15:1.1:1.1:1). Solvent front is taken as $7 \mathrm{~cm}$. After the successfull development, the plate was examined under UV chamber at $366 \mathrm{~nm}$. it is detected under UV camber at $366 \mathrm{~nm}$.
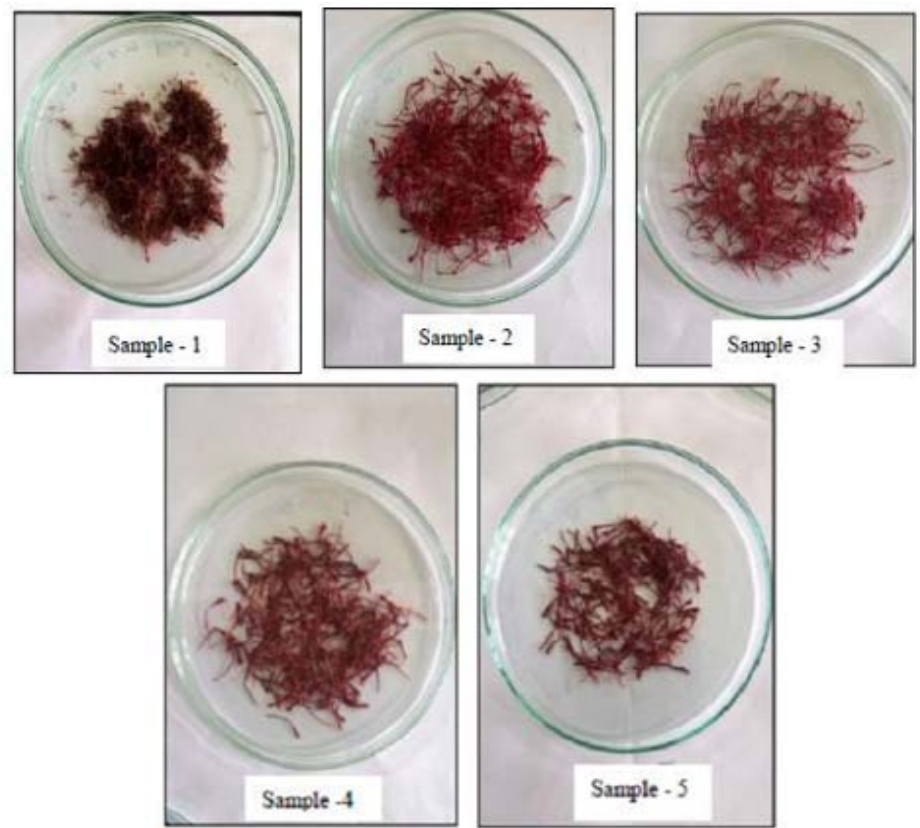

Plate 2: Market samples of Crocus sativus Linn

\section{RESULTS}

\section{TLC identity test-detecting the presence of safranal}

A band (Rf 0.437 and 0.87 ) corresponding to safranal is visible in both the standard and sample s5 test solution. Sample s1, s2, s3 and s4 does not showing the band corresponding to the safranal standard.
Antioxidant activity

\section{DPPH radical scavenging activity}

The higher level of antioxidant activity showed in sample5, 14.88\% in $100 \mu \mathrm{g} / \mathrm{ml}$. Ascorbic acid standard showing antioxidant activity in $14.89 \%$ and $7.26 \%$. Sample S5 showing the antioxidant activity 
Table 9: High-pressure thin layer chromatography-detection of flavonoids

\begin{tabular}{lll}
\hline Lane & Rf value & Colour of the band \\
\hline Lane1 & 0.23 & Green \\
Lane2 & 0.22 & Green \\
Lane3 & Not detected & - \\
Lane4 & 0.22 & Green \\
Lane5 & 0.23 & Green \\
Rutin (STD) & 0.29 & Yellow \\
\hline
\end{tabular}

Flavonoid content is different in different samples. It is present highly s1 and s5. sample s3 do not contain the Flavanoid. Previous studies Eshan, et al., 2012. Showing the difference in phenolic compounds in stigma extracts. These studies reporting the different solvents affected the total phenolic and flavonoids content of the exact. flavanoid content is detected in sample 1 , sample 2 , sample 4 , and sample 5 . The sample 3 does not show the presence of flavonoid. Rutin standard showing the maximum $\mathrm{Rf}$ value 0.29 and maximum flavonoid percentage is $100 \%$. Sample 5 showing starting Rf 0.22 and maximum Rf value 0.23 and maximum percentage of flavonoid content is $7.77 \%$. Sample 4 showing starting Rf 0.17 and maximum Rf value 0.22 and maximum percentage of flavonoid content is $7.64 \%$. Sample 1 showing starting Rf 0.20 and maximum $\mathrm{Rf}$ value 0.23 and maximum percentage of flavonoid content is $5.33 \%$. Sample 2 showing starting Rf 0.19 and maximum Rf value 0.22 and maximum percentage of flavonoid content is $6.60 \%$.

\section{DISCUSSION}

\section{TLC identity test-detecting the presence of safranal}

A band ( $R f 0.437$ and 0.87 ) corresponding to safranal is visible in both the standard and sample S5 test solution. Sample s1,s2,s3 and s4 did not show the band corresponding to the safranal standard. A band (Rf 0.64) corresponding to safranal is visible in both standards and test solution tracks [9]. These analytical method is simple, sensitive, rapid and specific safranal is a monoterpene aldehyde, formed in saffron by hydrolysis from picrocrocin during drying and storage. Safranal is present only in s5 sample. It is the main essential volatile oil responsible for the saffron characteristic such as odour.

\section{Total phenolic content}

Phenolic content is varied in different market samples. The amount of phenolic compounds in the saffron extract was determined using the Folin-ciocalteau reagent. Total phenolic content is the help to detect the pure and fake saffron. The phenolic content is higher in S5. Sample S5 showed $0.737 \mathrm{mg} / \mathrm{ml}$ phenolic content. Lowest level of phenolic content in sample S3. Sample S3 showed $0.0887 \mathrm{mg} / \mathrm{ml}$ phenolic content. Sample S4 showed $0.564 \mathrm{mg} / \mathrm{ml}$ total phenolic content. Sample S1 showed 0.416 $\mathrm{mg} / \mathrm{ml}$ total phenolic content and sample S2 showed $0.267 \mathrm{mg} / \mathrm{ml}$ phenolic content total phenolic contents results were expressed as milligrams of gallic acid equivalents per gram dry weight ${ }^{1}$. The saffron petal total phenolic content was $3.42 \mathrm{mg}$ gallic acid/g dry weight ${ }^{1}$. Phenolic content equivalent to gallic acid per gram dry weight. Phenolic content of the ethanolic extract was compared between various tissue types and stigma was found to have higher phenolic content $(8.28 \mu \mathrm{g} / \mathrm{g})$ followed by corm $(7.07 \mu \mathrm{g} / \mathrm{g})$ and leaf $(5.62 \mu \mathrm{g} / \mathrm{g})[10,11]$.

\section{Antioxidant activity}

\section{DPPH radical scavenging activity}

Antioxidant activity is higher in sample s5. and it is different in different market samples. Sample 5 stigma posses higher antioxidant activity. Sample S5 showing $14.88 \%$ antioxidant activity in $100 \mathrm{mg} / \mathrm{ml}$ concentration, $7.26 \%$ in $80 \mathrm{mg} / \mathrm{ml}$ concentration, $2.23 \%$ in $60 \mathrm{mg} / \mathrm{ml}$ concentration, $2.21 \%$ in $40 \mathrm{mg} / \mathrm{ml}$ and $1.01 \%$ in $20 \mathrm{mg} / \mathrm{ml}$ concentration. Sample S3 showed the lower antioxidant activity in $0.1 \%$ in $60 \mathrm{mg} / \mathrm{ml}$ concentration and $0.1 \%$ in $80 \mathrm{mg} / \mathrm{ml}$. Ascorbic acid standard showing $14.89 \%$ in $100 \mathrm{mg} / \mathrm{ml}$ concentration, $7.26 \%$ in 80 $\mathrm{mg} / \mathrm{ml}$ concentration, $4.56 \%$ in $60 \mathrm{mg} / \mathrm{ml}$ concentration, and $3.1 \%$ in 40 $\mathrm{mg} / \mathrm{ml}$ concentration, and $1 \%$ in $20 \mathrm{mg} / \mathrm{ml}$ concentration. Stigma showed the highest antioxidant activity followed by corm and leaf [11].
The activity of all the extracts was found to be concentration dependent and increased with increase in the concentration of the extract. DPPH and FRAP assay results revealed the antioxidant activities of saffron stigmas, however, the antioxidant activity was effected by the nature of the solvents used ${ }^{1}$. The DPPH method is a simple, practical and sensitive assay, which has been widely used to detect active antioxidants with scavenging capacity even in low concentration. The free radical scavenging activity (DPPH) assay indicated the study increase in the free radical scavenging activity by all the extracts and standards in the range of 0 to $300 \mathrm{mg} / \mathrm{ml}$. The ability of antioxidants to react with DPPH which is a stable free radical and its conversion to $\alpha, \alpha$-diphenyl- $\beta$-picryl hydrazine is expressed in \% DPPH inhibition. DPPH by accepting an electron loses its color and changes from purple to yellow. Discoloration degree indicates that the antioxidants possess scavenging potentials.

\section{HPTLC-high pressure thin layer chromatography-detection of flavonoids}

Flavonoid content is different in different samples. It is present highly present in sample s1 and s5. sample s3 do not contain the Flavanoid. Different solvents affected the total phenolic and flavanoids content of the extact ${ }^{1}$. The flavanoid contents were markedly higher in the methanolic extract,with a value of $5.88 \mathrm{mg}$ rutin equivalent/g DW compared to the boiling water extract at $3.86 \mathrm{mg}$ and ethanolic extract with a value of $2.91 \mathrm{mg}$ rutin equivalent/g DW. Flavonoids are widely distributed in plants, fulfilling many functions. Flavonoids are the most important plant pigments for flower coloration, producing yellow or red/blue pigmentation in petals designed to attract pollinator animals.

Flavanoid content is detected in sample 1 , sample 2 , sample 4 , and sample 5. The sample 3 does not show the presence of flavonoid. Rutin standard showing the maximum Rf value 0.29 and maximum flavonoid percentage is $100 \%$. Sample 5 showing starting Rf 0.22 and maximum $\mathrm{Rf}$ value 0.23 and maximum percentage of flavonoid content is $7.77 \%$. Sample 4 showing starting Rf 0.17 and maximum Rf value 0.22 and maximum percentage of flavonoid content is $7.64 \%$. Sample 1 showing starting Rf 0.20 and maximum Rf value 0.23 and maximum percentage of flavonoid content is $5.33 \%$. Sample 2 showing starting Rf 0.19 and maximum Rf value 0.22 and maximum percentage of flavonoid content is $6.60 \%$. saffron stigmas flavonoid contents were markedly higher in the methanolic extract,with a value of $5.88 \mathrm{mg}$ Rutin equivalent/g DW compared to the boiling water extract at $3.86 \mathrm{mg}$ and the ethanolic extracts with a value of $2.91 \mathrm{mg}$ Rutin equivalent/g DW ${ }^{1}$. The maximum flavonoid content present in the ethanolic extracts of stigma $(353 \pm 0.11)$ followed by corm $(2.46 \pm 0.28)$ and leaf $(1.61 \pm 0.12)$. Sample S5 showed higher flavonoid content [11].

\section{CONCLUSION}

Safranal is a monoterpene aldehyde. Sample s5 showed the presence of safranal. Saffron stigma was found to posses antioxidant activity, hence saffron is a promising natural product. Phenolic and flavonoid content is higher in sample 5. Sample 5 is rich in flavanoids and phenols, therefore, might show higher antioxidant activity. These methods can be employed for assessing the genuinity of the market samples of Crocus sativus Linn. The authenticity of saffron is an extremely important matter for the industry and for the consumers in view of security and protection, quality assurance, active properties and last but not least, economic impact. Despite the fluctuation in prices in international markets, saffron was and still remains the most expensive spice. The genuine saffron samples possess higher price value. The fake saffron available in market with lower price value. The quality of the saffron depends upon the price values. 


\section{ACKNOWLEDGMENT}

First of all I would like to show my deep sense of gratitude to the Almighty God whose unbounded ray of blessings enriched my thoughts and deeds and also gave good health, strength and self-confidence. I feel extremely honored for the opportunities given to me to work under the supervision of Dr. Divya. S. Balachandran, BAMS, MD. Assistant production manager, Oushadhi, Kuttanellur, Thrissur, for the continuous and valuable guidance and unstained encouragement through the course of these theses. I wish to take this opportunity to express my deep sense of gratitude and indebtedness to my esteemed guide Dr. Binu. T. V, Assistant professor on contract, Department of Botany, Vimala College Thrissur for her valuable guidance throughout my dissertation work.

My special thanks to the concerned authority of librarians of Kerala Forest Research Institute (KFRI) Peechi, Kerala Agricultural University Central Library, Mannuthy, for my literature collection.

\section{AUTHORS CONTRIBUTIONS}

All the author have contributed equally

\section{CONFLICT OF INTERESTS}

Declare none

\section{REFERENCES}

1. Ehsan Karimi, Ehsan Oskoueian, Rudi Hendra, Hawa ZE, Jaafar Evaluation of crocus sativus L. stigma phenolic and flavonoid compounds and its antioxidant activity. Molecules 2012;15:6244-56.

2. Anubha Ubadhyay, Preeti Sagar, Nayak Mukta, Misra Noor, Afshankhan Dwivedi SK, Rao S. Standardisation techniques for medicinal and aromatic plants; 2006;4:7-8.
3. Denys J Charles. Antioxident properties of spices,herbs and other sources. Frontier Natural Products Co-Op 2013. p. 509-16.

4. Nanda Amalesh, Paul Nirankush, Gupta Amartya Kumar, Ganguly Partha, Banerjee Dipankar, Sing Rahul, et al. Identification of adultrants by pharmacognostical evaluation: $t$ tvak (Cinnamomum Zeylanicum Blume.) and Naluka/Cassia [Cinnamomum Cassia (Nees and T. Nees.) J. Presl]. Int J Res Pharm Biosci 2015;2:1-4.

5. Ayoob Mantoo M, Farooq Ahamad Zaki. Advances in spices research, history and achievements of spices research in India since Independence. Agrobiose (India); 2006. p. 823-5.

6. Neeraj Tandon. Quality standards of Indian medicinal plant. Medicinal plants unit Indian council of medical research, New Delhi; 2013. p. 371-2

7. The Ayurvedic Pharmacopeia of India. (1 ${ }^{\text {st }}$ Ed.) Government of India, Ministery of health and family welfare, Department of Ayurveda, Yoga-Naturopathy, Unani, Sidda and Homeopathy (AYUSH), New Delhi; 2004. p. 59-60.

8. Khadabadi SS, Deore SL, Baviskar BA. Experimental phyto pharmacognosy-a comparative guide ( $2^{\text {nd }}$ Ed.). Nirali Prakashan; 2013. p. 2.8-4.9.

9. Neeraj, Tandon. Quality standards of Indian medicinal plants. Medicinal plants unit Indian council of medical research, New Delhi 2011;9:92-9.

10. Sayed Amir, Hossein Goli, Fereshteh Mokhtari, Mehdi Rahimmaiek. Phenolic compounds and antioxidant activity from saffron (Crocus sativus L.) petal. J Agric Sci 2012;4:175-81.

11. Shoib Ahamad Babu, Aubid Hussain Malik, Zahoor Ahamed Wani, Jabasum Mohinddin, Zeeshan Ahah, Nazia Abbas, et al. Phytochemical analysis of antioxidant activity of different tissue types of crocus sativus and oxidative stress alleviating potential of saffron extract in plants, bacteria and yeast. South Afr J Bot 2015;99:80-7. 